Research Article

\title{
Critical Analysis and Application of Net-Metering Practice in MEPCO
}

\author{
Hassan Zahid, ${ }_{1}^{1}$ Farhana Umer ${ }^{D},{ }^{1}$ Zeeshan Rashid ${ }^{D},{ }^{1}$ Abdur Raheem, ${ }^{1}$ Rabia Shakoor, ${ }^{1}$ \\ and G. Amjad Hussain ${ }^{2}$ \\ ${ }^{1}$ Department of Electrical Engineering, Islamia University of Bahawalpur Pakistan, Pakistan \\ ${ }^{2}$ School of Engineering and Applied Sciences, American University of Kuwait, Kuwait \\ Correspondence should be addressed to Farhana Umer; farhana.umer@iub.edu.pk
}

Received 10 January 2020; Accepted 24 March 2020; Published 13 June 2020

Academic Editor: Leonardo Palmisano

Copyright ( 2020 Hassan Zahid et al. This is an open access article distributed under the Creative Commons Attribution License, which permits unrestricted use, distribution, and reproduction in any medium, provided the original work is properly cited.

\begin{abstract}
The electrical infrastructure around the globe is expanding at a rapid rate for the sake of fulfilling power demands in the domestic, commercial and entertainment industries aiming to boost the living standards. In this regard, renewable energy sources (RES) are globally accepted potential candidates for maintaining inexhaustible, clean, and reliable electricity with a supplementary feature of economic prospect. The efficiency of power distribution at reduced cost to the consumers can be further enhanced by introducing a two-way billing system so-called net-metering which has the potential to overcome issues such as voltage regulation, power blackouts, overstressed grid and need for expensive storage systems thereby making it beneficial for the grid and the end user. This envisioning has encouraged the Government of Pakistan to install net-metering infrastructure at places which accommodate surplus renewable energy reserves. According to the Electric Power Act 1997, the National Electric Power Regulatory Authority (NEPRA) issued the net-metering rules and regulations in September 2015 by the endorsement of Federal Government which allowed the distribution companies in Pakistan to buy surplus electricity units generated by the consumers in order to partly reimburse the units imported from the utility grid. The aim behind this research work is to promote renewable energy utilization through net-metering mechanism in order to achieve maximum power. The export of units from consumer side to utility grid and vice versa can be made through bidirectional energy meter. In this paper, a solar net-metering analysis has been carried out on ETAP software to determine its benefits in a distribution network. Different scenarios have been investigated, and it is concluded that solar net-metering technique has multiple influential benefits, e.g., improvement in voltage regulation, reduction in transmission and distribution losses, increase in power availability, less billing to consumers, and reduction of loading on utility grid.
\end{abstract}

\section{Introduction}

In Pakistan, the energy demand is growing by more than nine percent annually, and it is predicted that an increase in energy demand will be eightfold by 2030 and twenty-fold by 2050 [1]. Among all developing countries, Pakistan is also in a race of development and in order to conform to its huge load demand, Pakistan requires expanding the scale of power network to be able to maintain the balance between energy supply and demand. Due to the continuous and overwhelming population growth in the country, the supply of electricity is lagging behind the demand and due to this significant imbalance, a severe load shedding of 10 to 12 hours in urban areas and 16 to 18 hours in rural areas is taking place in summer [2]. The best and feasible solution to overcome this energy gap is to promote renewable energy on an individual basis and develop awareness for its efficient utilization through net-metering. The renewable energy sources such as wind, tidal, geothermal, and solar energy can be accessible in excess quantity, and the dramatic increase in energy demand can be easily maintained with them [3]. Netmetering is an advanced billing mechanism which has the capability to run the meter in backward direction when electricity is credited to the grid during off-peak hours; thus, units are sold by the consumer. Now with the help of Alternative Energy Development Board (AEDB), National 
Electric Power Regulatory Authority (NEPRA) and concerned Distribution Companies (DISCOS), the Government of Pakistan is motivating people to draw their attention towards net-metering by promoting renewable energy so that the investments can be made on renewable energy sector at small/individual level. In 2015, the rules and standards on a net-metering scheme were defined by NEPRA by allowing DISCOS to take/purchase excess energy units generated by renewable energy sources from consumer side at the same rates prescribed by the company [4].

In a modernized era of technological advancements, netmetering adoption has expanded in a significantly influential manner in the power sector. The net-metering mechanism is of great interest for renewable energy users, e.g., wind and solar. Net-metering is a scheme by which electric power can be transferred to an electric grid on the same rates prescribed by the distribution companies at which consumer is being charged. For renewable energy users such as solar and wind energy, the net-metering mechanism is very attractive as it allows the end users to consume all their generated electrical energy, depending upon their need or to transfer extra electrical energy/all generated electrical energy to utility grid by bidirectional billing mechanism. When required, the extra exported electrical energy can again be drawn on the same rates as it was transferred to the utility grid. During this process, the electric grid behaves like a storage device (battery) to solar energy or wind energy users thereby eliminating the need for dedicated battery banks [5]. The block diagram of the net-metering mechanism is shown below in Figure 1.

In terms of geography, Pakistan is full of renewable energy sources especially solar energy and is located in a very attainable solar range where sunshine's up to 7 to 8 hours regularly in winter and 11 to 12 hours regularly in a summer season. Although, the weather conditions, e.g., humidity, dust, fog, and clouds also affect the solar irradiance, yet, the amount of solar energy reaching the earth is about $80 \%$ in clear and bright days. Having such a special geographical area, Pakistan receives the solar radiations continuously the whole year, and average solar radiation is approximately 9 hours [6]. The annual direct solar irradiation values in all four provinces of Pakistan are shown in Table 1.

The installation of a rooftop PV system through a netmetering mechanism can meet increasing energy demand [7]. This will not only reduce the burden on the power system but also reduces transmission and distribution losses.

Due to the best geographical area, Pakistan has aimed to set about 10 GWh from renewable energy until 2030 [8]. With the collaboration of AEDB, the Government of Pakistan is playing a vital role for the promotion and the advancement of solar power in Pakistan. In 2006, AEDB abolished the tax duties on solar energy products for the purpose of promoting and increasing the solar technology in Pakistan [8]. One of the examples for the advancement of solar power within Pakistan is by setting up the world's largest solar power plant named Quaid-e-Azam Solar Park (QASP). QASP is located in Bahawalpur (Punjab) having a capacity of $1000 \mathrm{MW}$ with Commercial Operation Date (COD) set for 2020 [9]. Up to now, 4 units are in operation and synchronized with the national grid, each having a $100 \mathrm{MW}$ capacity [9].

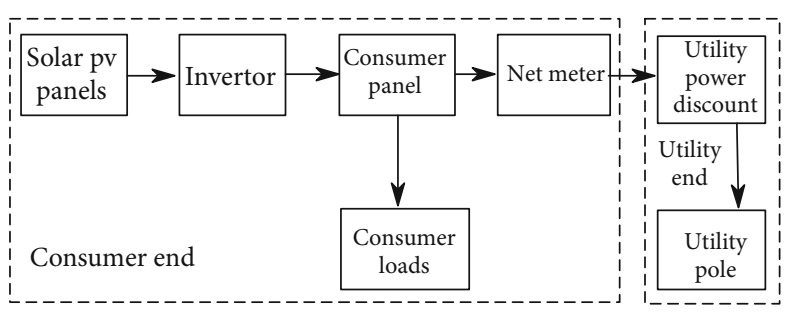

FIGURE 1: Block-diagram of net-metering mechanism [5].

TABle 1: Pakistan all provinces solar irradiance [6].

\begin{tabular}{lcc}
\hline Province name & $\begin{array}{c}\text { Min. solar irradiation } \\
\left(\mathrm{kWh} / \mathrm{m}^{2} / \text { day }\right)\end{array}$ & $\begin{array}{c}\text { Max. solar irradiation } \\
\left(\mathrm{kWh} / \mathrm{m}^{2} / \text { day }\right)\end{array}$ \\
\hline Punjab & 6.5 & 7 \\
Baluchistan & 7 & 7.5 \\
Sindh & 5 & 5.5 \\
KPK & 4.5 & 5 \\
\hline
\end{tabular}

\section{Literature Review}

In former times, the net-metering scheme was firstly adopted by the USA where the solar energy or wind energy was synchronized with the grid network. This system was introduced for the users of renewable energy because they were interested to use all their generated electrical energy at different times according to their demand. In 1981, the first state that passed the net-metering license was Minnesota [10]. After Minnesota, many other states also passed the net-metering scheme license, since the interest behind this law was only to feed excess energy to utility grids on the rates prescribed by concerned distribution companies. Up to now, 42 states have adopted and implemented the net-metering in USA [10].

In the Philippines, the net-metering mechanism was initiated by the Renewable Energy Act (REA) 2008, and its Implementing Rules and Regulation (IRR). The Energy Regulatory Commission (ERC) is the implementing body which is in coordination with the National Renewable Energy Board (NREB) [11]. In 2013, a net-metering scheme was also started in Cyprus with the cooperation of the Cyprus Energy Regulatory Authority (CERA) [12]. The interest behind this scheme was to promote the rooftop installation of the PV system in Cyprus as a sign of clean and environmental friendly energy. After the first promotion of a net-metering scheme in Cyprus, the rooftop installations of PV started becoming popular on the individual basis because of the interest and simplicity of the net-metering policy offered in Cyprus. The Cyprus that lies in the Eastern side of the Mediterranean region has the greatest solar irradiance and photovoltaic potential of Europe [12]. The yearly (horizontal) irradiance in hilly areas lies between the ranges of 1800 to $1900 \mathrm{kWh} / \mathrm{m}^{2}$ and in seaside areas/inner-side of the country lies between 1900 to $2100 \mathrm{kWh} / \mathrm{m}^{2}$ [12].

Due to the fast economic growth in the past few years, many southeast countries are planning to equalize rapid economic development with long-range renewability goals. Due to this upgradation, several countries have aimed to increase 
their renewable energy share within their national grids. Recently the attention has inflated to promote the renewable energy sources on small-scale geared towards commercial as well as residential areas [13]. Among these aimed countries, Malaysia, Singapore, Thailand, Philippines, and Indonesia have initiated frameworks for its residential users to install rooftop PV systems. Recently, Indonesia also introduced a net-metering scheme [13]. Thailand and Malaysia are also initiating a net-metering mechanism [9].

In India, Maharashta was the first state to availed netmetering. The first bidirectional meter was installed in Verdean Industries Ltd. by Tata Power Company. Afterwards, further $25 \mathrm{~kW}$ of solar metering was installed at Vatic-Nagar word office. Some other projects were also effectively installed by Rooftop-Urjacomopany, i.e., $3 \mathrm{~kW}$ solar net-metering system at Telangana, $15 \mathrm{~kW}$ solar netmetering system at Karnataka, $10 \mathrm{~kW}$ solar net-metering system at Karnataka [14].

Many distribution companies are promoting solar netmetering mechanism to residential level. Several states in the United States of America and also in Japan have executed a net-metering mechanism where generated electricity is selfconsumed before feeding surplus electricity to the utility grid. On the other side, Germany is widely known for the thriving execution of the gross-metering scheme [15].

India is also known for its fervent solar energy, where solar radiations are accessible for longer durations on a daily basis. As solar energy has much potential to overcome energy losses. Therefore, the National Solar Mission was planned by India [16]. The aim of National Solar Mission was to increase generation capacity by technological innovation and also to drop down the cost of electricity as low as possible. The mission consists of three-stage approach. The $1^{\text {st }}$ approach (i.e., 2010-2013) is promoting off-grid system which comprises of grid-tied solar power generation to $1000 \mathrm{MW}$. The $2^{\text {nd }}$ approach (i.e., 2014-2017) comprises of further $3000 \mathrm{MW}$ or more grid-tied solar power generation. The $3^{\text {rd }}$ phase (i.e., 2017-2022) will comprise of $20000 \mathrm{MW}$ or more grid-tied solar power generation [16].

In Gujarat, power generation through net-metering scheme aims to set up to $5 \mathrm{MW}$ of power, i.e., $1 \mathrm{MW}$ in private society and $4 \mathrm{MW}$ in government buildings [15].

\section{Methodology}

In this paper, an $11 \mathrm{kV}$ feeder named "CITY-3, Azeem Abad" is chosen for solar net-metering analysis which is emanating out from the $132 \mathrm{kV}$ grid station, Burewala in the region of Multan electric power company (MEPCO). The grid voltage is stepped down by 160 distribution transformers (3-phase) from $11 \mathrm{kV}$ to $415 \mathrm{~V}$ at which multiple loads are connected. For the convenience of easiness in simulation, these 160 distribution transformers are combined to form 8 distribution transformers. Table 2 shows the detail of the total 3-phase distribution transformers of CITY-3 feeder [17].

From CITY-3 feeder, a consumer named M. Sarwar from Punjab College (PC), Azeem Abad, Burewala is utilizing its own solar electricity having availed the solar net-metering scheme. The sectioned load of this consumer is $170 \mathrm{~kW}$ and
TABLE 2: CITY-3 feeder distribution transformers [17].

\begin{tabular}{lc}
\hline Transformer (KVA) & Quantity \\
\hline 10 & 4 \\
15 & 7 \\
25 & 77 \\
50 & 23 \\
75 & 1 \\
100 & 25 \\
200 & 20 \\
400 & 1 \\
630 & 2 \\
Total & 160
\end{tabular}

TABLE 3: Status of net-metering applicant, MEPCO [17].

\begin{tabular}{lc}
\hline \multicolumn{2}{c}{ Net-metering applicant status } \\
Name of applicant & M. Sarwar (PC Burewala) \\
\hline Sub division codes & 15333 \\
Feeder name & CITY-3 Azeem Abad \\
Sectioned load & 170 \\
Generation license & DGL/620/2018 \\
Installation status & Installed \\
Billing started & Yes \\
Solar generation $(\mathrm{kW})$ & 192 \\
\hline
\end{tabular}

the generation capacity of solar net-metering is 192 . With the help of bidirectional meter, this solar net-metering user is exporting excess electricity to the utility grid when its generation is more than its power demand. In this research work, we simulate this feeder and perform load flow analysis with and without solar net-metering. The purpose of this simulation is to implement a net-metering scheme in MEPCO using electric transient and analysis program (ETAP) software. Another main reason is to promote a solar net-metering scheme in Pakistan. At the end, we do a comparison of voltage levels, distribution losses, and line losses with and without a solar net-metering scheme. The Table 3 shown below indicates the status of a net-metering applicant on which simulation has to be performed [17].

In this paper, a different number of cases are performed with respect to Bus22 on CITY-3 feeder with solar netmetering mechanism, and critical analysis, i.e., load flow analysis and harmonics analysis are also carried out on ETAP. The Bus22 is selected subject to the net-metering status of MEPCO [17]. Multiple loads are connected on N-M network transformer as shown in Figure 2(b). Out of these loads, the only PC Burewala load had installed a solar system of $192 \mathrm{~kW}$ and had availed net-metering. As the scope of this paper is to promote the net-metering scheme and to show its notable advantages on the distribution system. So in the light of the above points, the Bus 22 is selected. The following cases are performed:

Case 1. Load flow analysis of CITY-3 feeder with Bus22 load ON/solar power OFF. 


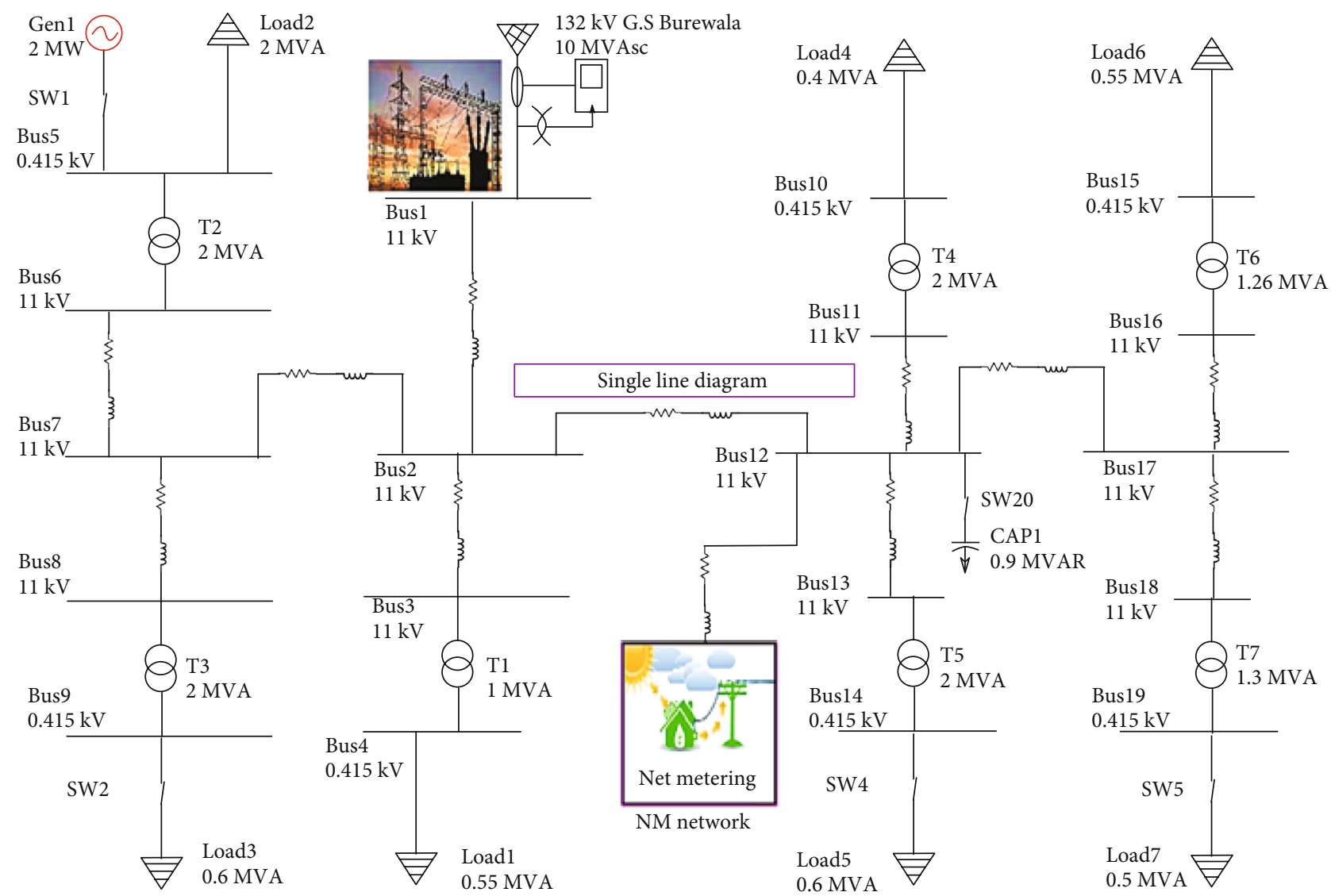

(a)

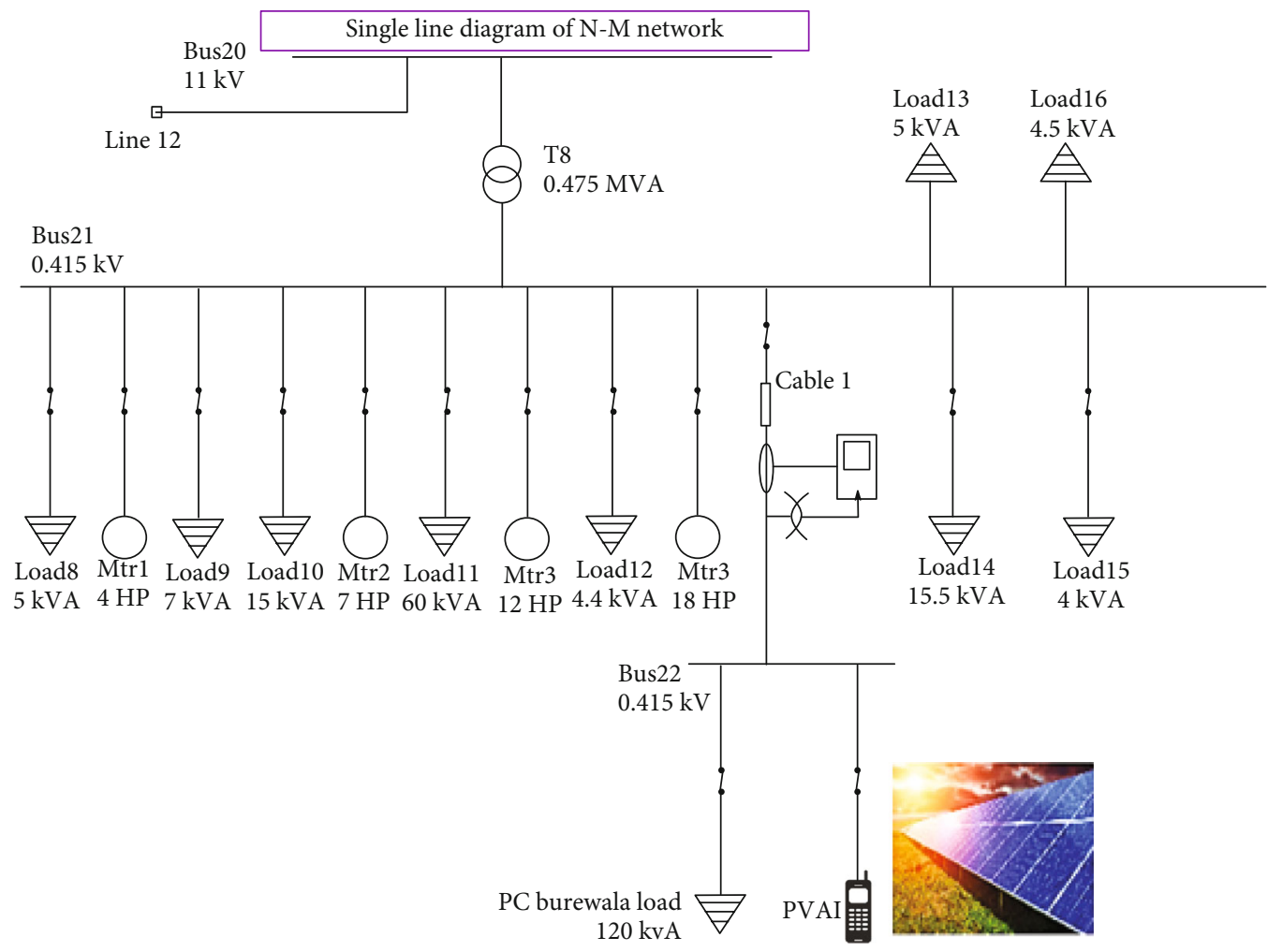

(b)

Figure 2: (a) Single line diagram of CITY-3 feeder (MEPCO). (b) Single line diagram of net-metering network. 


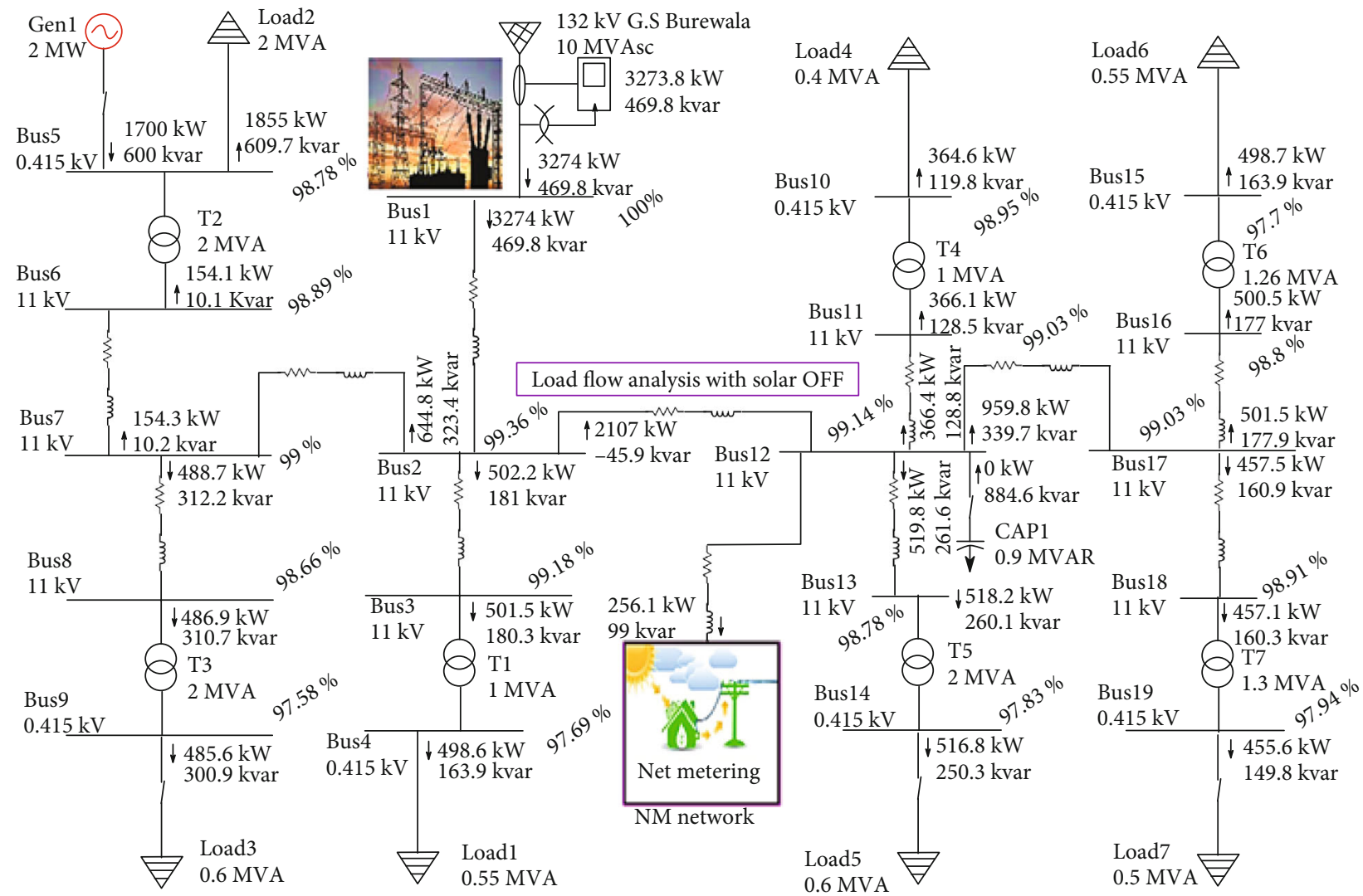

(a)

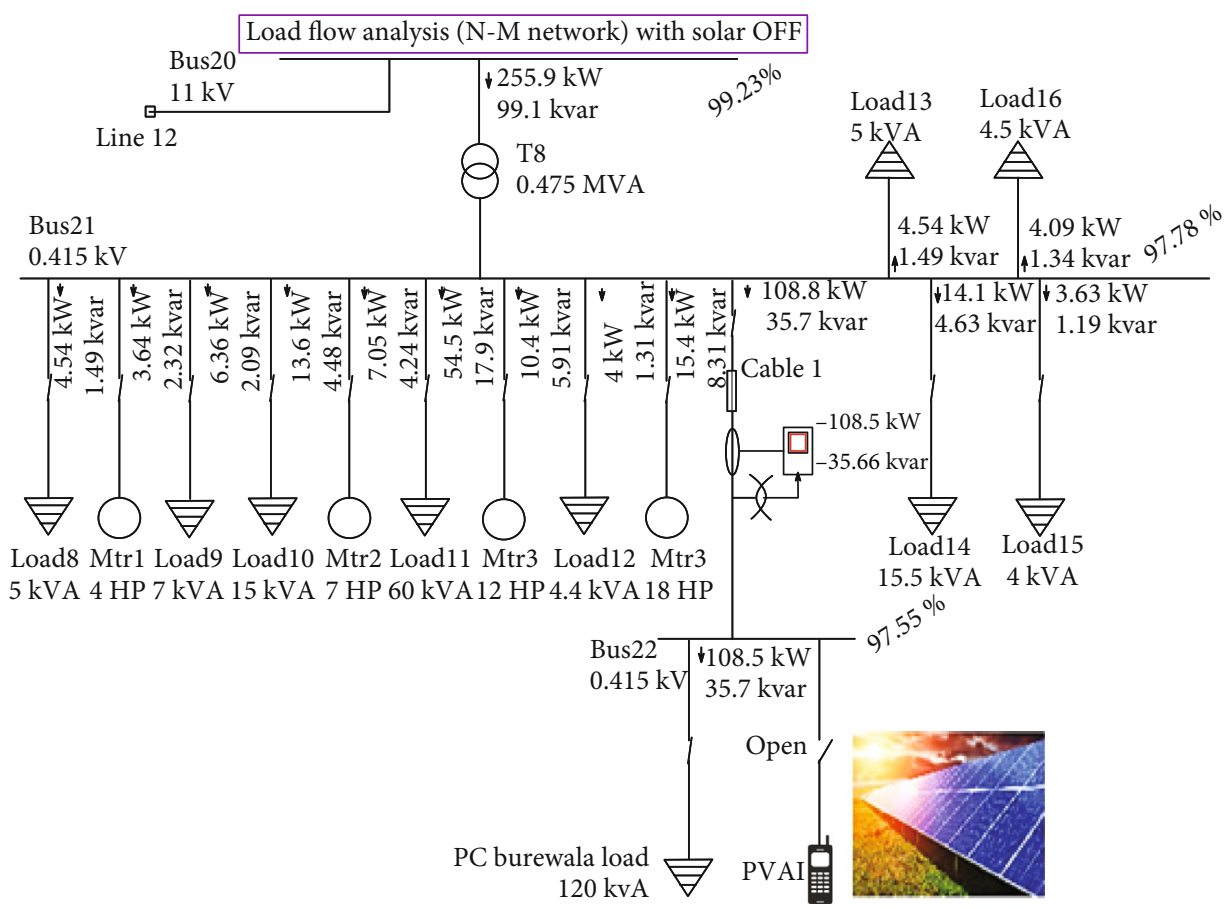

(b)

FIGURe 3: (a) Load flow analysis with Bus22 load ON/solar power OFF. (b) Load flow analysis (N-M network) with Bus22 load ON/solar oower OFF. 
Case 2. Load flow analysis of CITY-3 feeder with Bus22 load ON/solar power ON.

Case 3. Load flow analysis of CITY-3 feeder with Bus22 load OFF/solar power ON.

\section{Load Flow Analysis and Results}

A single line diagram of CITY-3 feeder represents a 3-phase power system as shown in Figure 2(a). For the sake of consideration, a single line diagram of the solar net-metering mechanism is separately shown in a new network/window (N-M network) and is connected with the feeder as shown below in Figure 2(b). The reason to make a separate network is to observe the prominent effects of solar net-metering in a distribution network.

4.1. Case 1, Load Flow Analysis with Bus22 Load ON/Solar Power OFF. In the first case, the solar power generation is not available (during night or cloudy weather condition), and the load Bus22 of PC Burewala is drawing all the required power from the utility grid as shown in Figures 3(a) and 3(b). In this case, the voltage on load bus Bus 21 of N-M network is $408 \mathrm{~V}$, while the nominal voltage is $415 \mathrm{~V}$. It can be seen that there is a voltage drop of 8 volts across load Bus21. In addition, there is an additional burden of $120 \mathrm{~kW}$ (PC Burewala load) on utility grid as PC Burewala load is drawing all the required power from the grid station, resulting in increase in transmission and distribution losses. In this case, load flow analysis shows the real and reactive power flowing within the network, the buses voltage levels as well as the transmission and transformation losses in a distribution network which can be seen in reports generated by the load flow study analysis in ETAP.

It can be seen in Figure 3(b) that the solar power is OFF which means the solar is not feeding power to Bus22, and all the power is coming from the utility grid to Bus 22 to feed PC Burewala load as shown by multimeter. As seen by multimeter, the active and reactive power consumption of PC Burewala load is $-109.5 \mathrm{~kW}$ and $-35.99 \mathrm{kVAR}$.

The negative sign depicts that the load is drawing both real power and reactive power from the utility grid. The voltage profile of the feeder can also be observed from the utility grid, $11 \mathrm{kV}$ feeder to the load Bus 22 of PC Burewala. The Table 4 shows the comparison of voltages on different buses between nominal voltage and observed voltage profile percentage in Case 1.

The Table 5 shown below shows the load flow on relevant buses of the net-metering network for Case 1 .

It can be seen from the Table 5 that there is a load of $108.5 \mathrm{~kW}$ on Bus22 and the solar power is OFF (no generation on Bus22), and voltage profile on main load Bus21 of the net-metering network is $97.78 \%$ and on PC Burewala load Bus 22 is $97.55 \%$. A complete feeder is drawing $3274 \mathrm{~kW}$ and $469.8 \mathrm{kVAR}$ power from the utility grid as shown in Figure 3(a). The negative sign with 0.109 MW on Bus 22 shows that the PC Burewala load on Bus22 is extracting power from the utility grid.
TABLe 4: Voltage profile in Case 1.

\begin{tabular}{lcc}
\hline Bus ID & Nominal voltage $(\mathrm{V})$ & Observed voltage level (\% age) \\
\hline Bus1 & 11000 & 100 \\
Bus2 & 11000 & 99.36 \\
Bus3 & 11000 & 99.18 \\
Bus4 & 415 & 97.69 \\
Bus5 & 415 & 98.78 \\
Bus6 & 11000 & 98.89 \\
Bus7 & 11000 & 99 \\
Bus8 & 11000 & 98.66 \\
Bus9 & 415 & 97.58 \\
Bus10 & 415 & 97.95 \\
Bus11 & 11000 & 99.03 \\
Bus12 & 11000 & 99.14 \\
Bus13 & 11000 & 98.78 \\
Bus14 & 415 & 97.83 \\
Bus15 & 415 & 97.7 \\
Bus16 & 11000 & 98.8 \\
Bus17 & 11000 & 99.03 \\
Bus18 & 11000 & 98.91 \\
Bus19 & 11000 & 97.94 \\
Bus20 & 11000 & 99.06 \\
Bus21 & 415 & $\mathbf{9 7 . 7 8}$ \\
Bus22 & 415 & $\mathbf{9 7 . 5 5}$ \\
\hline
\end{tabular}

TABle 5: Load flow of N-M network for Case 1.

\begin{tabular}{lcccc}
\hline \multirow{2}{*}{ Bus ID } & \multicolumn{2}{c}{ Voltage } & \multicolumn{2}{c}{ Load flow } \\
& $\mathrm{kV}$ & \% mag. & MW & MVAR \\
\hline 20 & 11.000 & 99.065 & -0.256 & -0.099 \\
21 & 0.415 & 97.779 & -0.255 & -0.092 \\
22 & 0.415 & 97.555 & -0.108 & -0.036 \\
\hline
\end{tabular}

TABLE 6: Branch losses for Case 1.

\begin{tabular}{lccc}
\hline Branch ID & $\begin{array}{c}\text { Losses } \\
\mathrm{kW}\end{array}$ & Branch ID & $\begin{array}{c}\text { Losses } \\
\mathrm{kW}\end{array}$ \\
\hline Line1 & 18.8 & Line12 & 0.2 \\
Line2 & 0.8 & Cable1 & 0.3 \\
Line3 & 2.1 & $\mathrm{~T} 1$ & 2.8 \\
Line4 & 0.2 & $\mathrm{~T} 2$ & 1.1 \\
Line5 & 1.4 & $\mathrm{~T} 3$ & 1.4 \\
Line6 & 4.8 & $\mathrm{~T} 4$ & 1.5 \\
Line7 & 0.3 & $\mathrm{~T} 5$ & 1.4 \\
Line8 & 1.6 & $\mathrm{~T} 6$ & 1.8 \\
Line9 & 0.9 & $\mathrm{~T} 7$ & 1.5 \\
Line10 & 1.0 & $\mathrm{~T} 8$ & 1.3 \\
Line11 & 0.4 & & \\
Total losses $(\mathrm{kW})$ & & & 45.6 \\
\hline
\end{tabular}




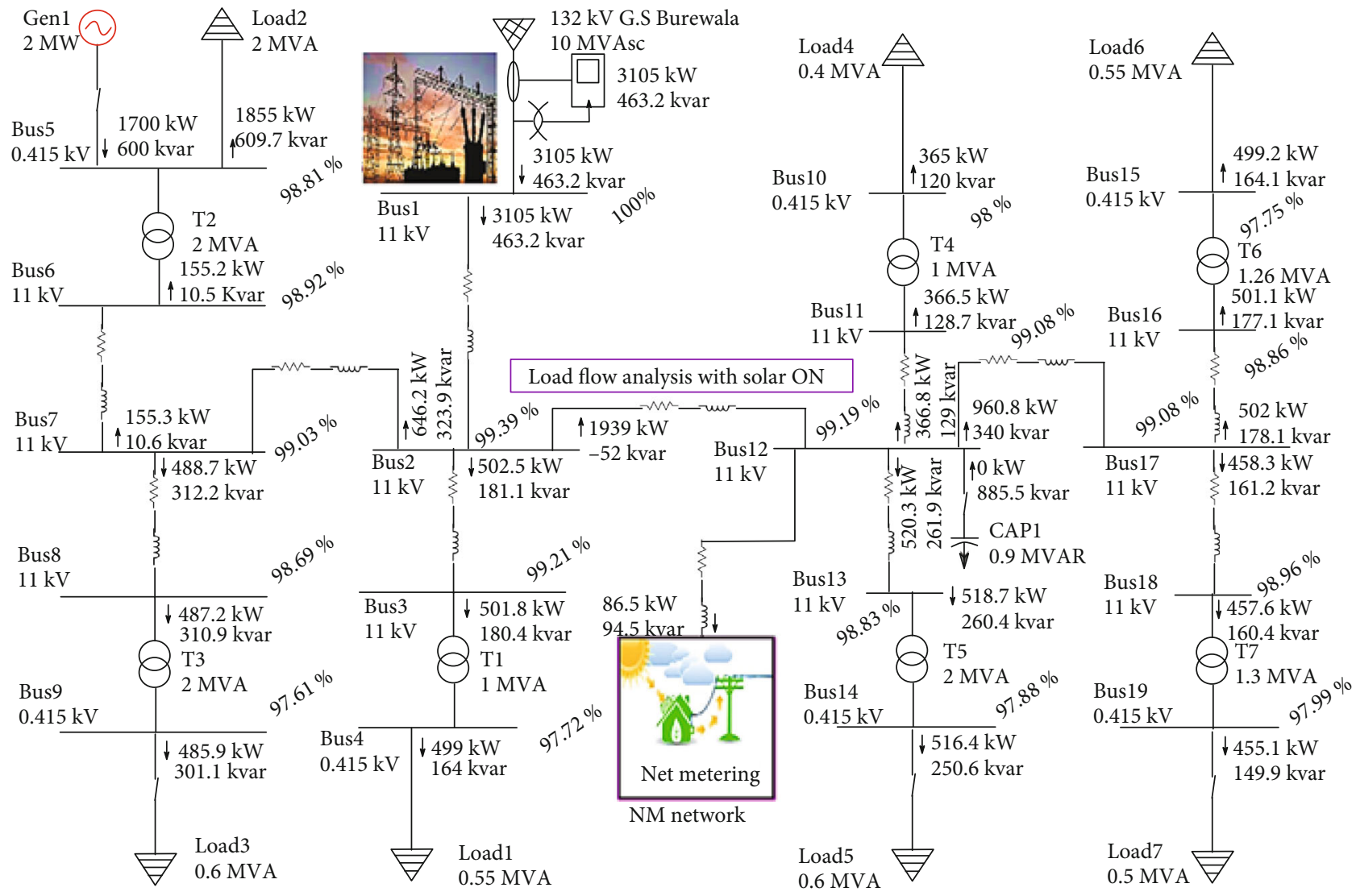

(a)

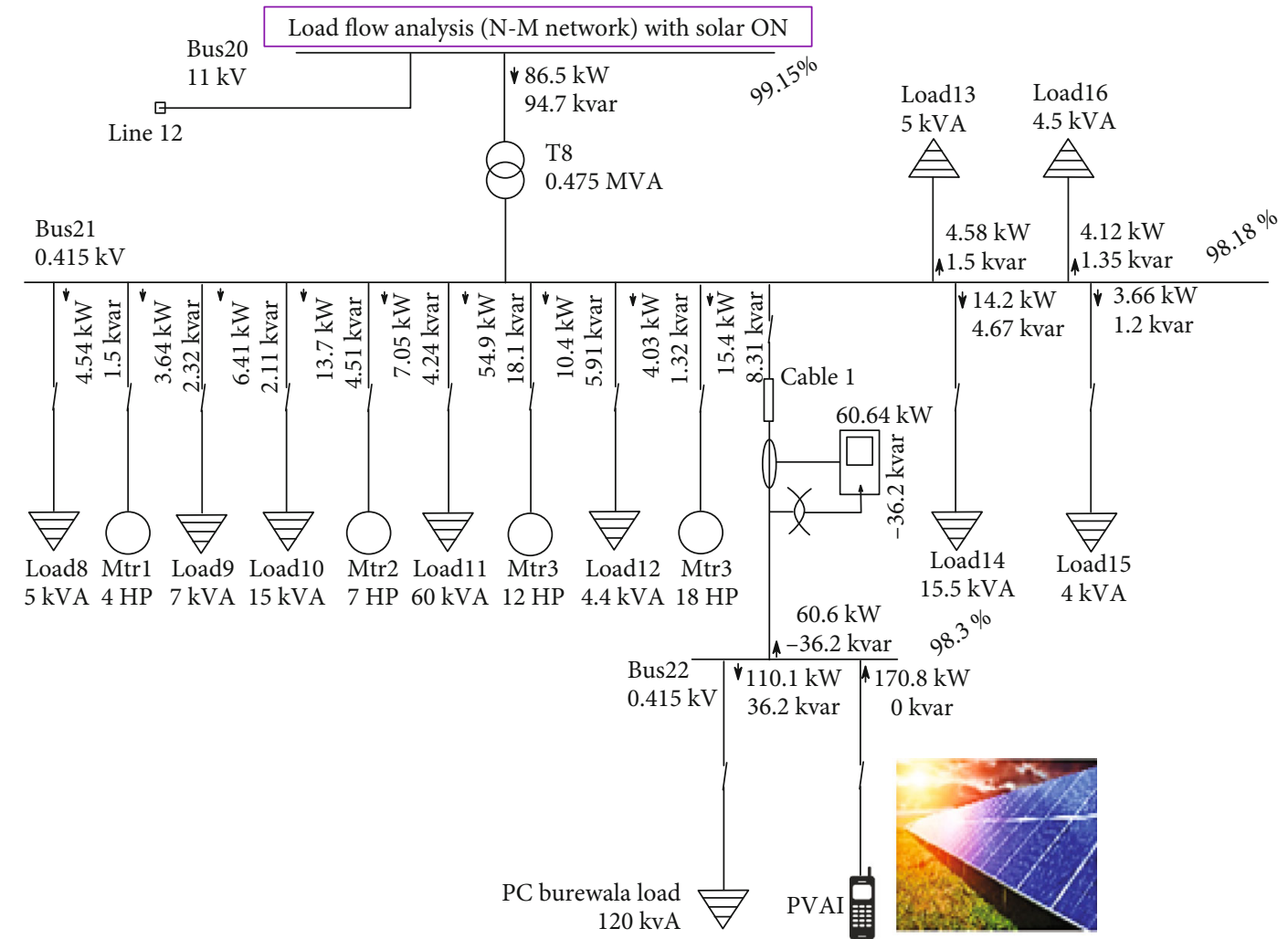

(b)

FIGURE 4: (a) Load flow analysis with Bus22 load ON/solar ON. (b) Load flow analysis (N-M network) with Bus22 load ON/solar ON. 
TABLE 7: Voltage profile in Case 2.

\begin{tabular}{lcc}
\hline Bus ID & Nominal voltage $(\mathrm{V})$ & Observed voltage level (\% age) \\
\hline Bus1 & 11000 & 100 \\
Bus2 & 11000 & 99.39 \\
Bus3 & 11000 & 99.21 \\
Bus4 & 415 & 97.72 \\
Bus5 & 415 & 98.81 \\
Bus6 & 11000 & 98.92 \\
Bus7 & 11000 & 99.03 \\
Bus8 & 11000 & 98.69 \\
Bus9 & 415 & 97.61 \\
Bus10 & 415 & 98 \\
Bus11 & 11000 & 99.08 \\
Bus12 & 11000 & 99.19 \\
Bus13 & 11000 & 98.83 \\
Bus14 & 415 & 97.88 \\
Bus15 & 415 & 97.75 \\
Bus16 & 11000 & 98.86 \\
Bus17 & 11000 & 99.08 \\
Bus18 & 11000 & 98.96 \\
Bus19 & 11000 & 97.99 \\
Bus20 & 11000 & $\mathbf{9 9 . 1 5}$ \\
Bus21 & 415 & $\mathbf{9 8 . 1 8}$ \\
Bus22 & 415 & $\mathbf{9 8 . 3}$ \\
\hline & &
\end{tabular}

Branch losses in Case 1: Table 6 shows the branch losses report of CITY-3 feeder.

Table 6 shows that the total losses of the system in Case 1 when PC Burewala load is ON and solar power is OFF are $45.6 \mathrm{~kW}$. All these values are of importance from the comparison point of view when solar is generating power, (solar ON) to meet consumer demand and feeding surplus energy to the utility grid.

4.2. Case 2: Load Flow Analysis with Bus22 Load ON/Solar Power. In Case 2, the solar power is available (i.e., Solar $\mathrm{ON}$ ) feeding the Bus22 load and exporting surplus power to the utility grid. Due to net-metering phenomena, a number of notable changes can be observed in a distribution network which can be visible in corresponding load flow and branch losses results. It can be seen that, in Case 1, when solar was OFF, the complete feeder was drawing $3274 \mathrm{~kW}$ from the utility grid, but in this case, when solar is $\mathrm{ON}$, the complete feeder is drawing $3105.1 \mathrm{~kW}$ from the utility grid which shows that solar net-metering mechanism reduces the burden on utility grid as well as the dependency of the netmetering user on utility grid as shown in Figure 4(a). In this case, the multimeter on PC Burewala load side shows the reading of $60.64 \mathrm{~kW}$ and $-36.3 \mathrm{kVAR}$ as shown below in Figure 4(b). The positive sign with real power $60.64 \mathrm{~kW}$ shows that the solar is feeding extra power to the utility grid, whereas the negative sign with reactive power $-36.3 \mathrm{kVAR}$ shows that the load is taking reactive power from the utility grid as solar only generates real power.
TABLE 8: Load Flow of N-M Network for Case 2.

\begin{tabular}{lcccc}
\hline \multirow{2}{*}{ Bus ID } & \multicolumn{2}{c}{ Voltage } & \multicolumn{2}{c}{ Load flow } \\
& $\mathrm{kV}$ & \% mag. & MW & MVAR \\
\hline 20 & 11.000 & 99.155 & -0.086 & -0.095 \\
21 & 0.415 & 98.180 & -0.085 & -0.093 \\
22 & 0.415 & 98.296 & 0.061 & -0.036 \\
\hline
\end{tabular}

TABLE 9: Branch losses for Case 2.

\begin{tabular}{lccc}
\hline Branch ID & $\begin{array}{c}\text { Losses } \\
\mathrm{kW}\end{array}$ & Branch ID & $\begin{array}{c}\text { Losses } \\
\mathrm{kW}\end{array}$ \\
\hline Line1 & 17.7 & Line12 & 0.1 \\
Line2 & 0.8 & Cable1 & 0.1 \\
Line3 & 2.1 & $\mathrm{~T} 1$ & 2.8 \\
Line4 & 0.2 & $\mathrm{~T} 2$ & 0.1 \\
Line5 & 1.4 & $\mathrm{~T} 3$ & 1.4 \\
Line6 & 3.1 & $\mathrm{~T} 4$ & 1.5 \\
Line7 & 0.3 & $\mathrm{~T} 5$ & 1.4 \\
Line8 & 1.6 & $\mathrm{~T} 6$ & 1.8 \\
Line9 & 0.9 & $\mathrm{~T} 7$ & 1.5 \\
Line10 & 1.0 & $\mathrm{~T} 8$ & 0.3 \\
Line11 & 0.4 & & \\
Total losses $(\mathrm{kW})$ & & & 40.5 \\
\hline
\end{tabular}

TABle 10: Branch losses comparison of Case 1 and Case 2.

\begin{tabular}{lc}
\hline Branch losses in Case 1, when solar OFF & $45.6 \mathrm{~kW}$ \\
\hline Branch losses in Case 2, when solar ON & $40.5 \mathrm{~kW}$ \\
\hline
\end{tabular}

Improved branch losses by solar net-metering mechanism $5.1 \mathrm{~kW}$

In Case 2, the voltage level across all the busses of a distribution network especially in N-M network on main load Bus 21 is $98.18 \%$, and on solar net-metering associated load Bus22 is $98.3 \%$. In previous case (i.e., solar OFF), the voltage level on these two busses was $97.78 \%$ on Bus 21 and $97.55 \%$ on Bus 22 which clearly depicts that solar net-metering improves voltage profile across load as well as feeding surplus power to the utility grid also improves voltage profile of the system that makes the power system more stable as well as improves the quality of power supply to the consumer.

In Case 2, a complete feeder is drawing $3105 \mathrm{~kW}$ real power and $463.2 \mathrm{kVAR}$ reactive power from the utility grid as shown in Figures 4(a) and 4(b), while in Case 1 (i.e., solar OFF), the power drawn by the utility grid is $3274 \mathrm{~kW}$ and $469.8 \mathrm{kVAR}$. The solar power is generating $170 \mathrm{~kW}$ out of which $110.1 \mathrm{~kW}$ is consumed by the associated PC Burewala load, and extra power of $60.64 \mathrm{~kW}$ is fed to the utility grid. Table 7 shows the comparison between nominal voltages and the observed voltage profile at different busses in Case 2.

The load flow shown in Table 8 shows the load flow and voltage profile on relevant buses, i.e., Bus20, Bus21, and Bus22 of N-M network for Case 2.

It can be observed from the Table 8 when solar power generation of $170.8 \mathrm{~kW}$ is on Bus 22 and voltage profile on 


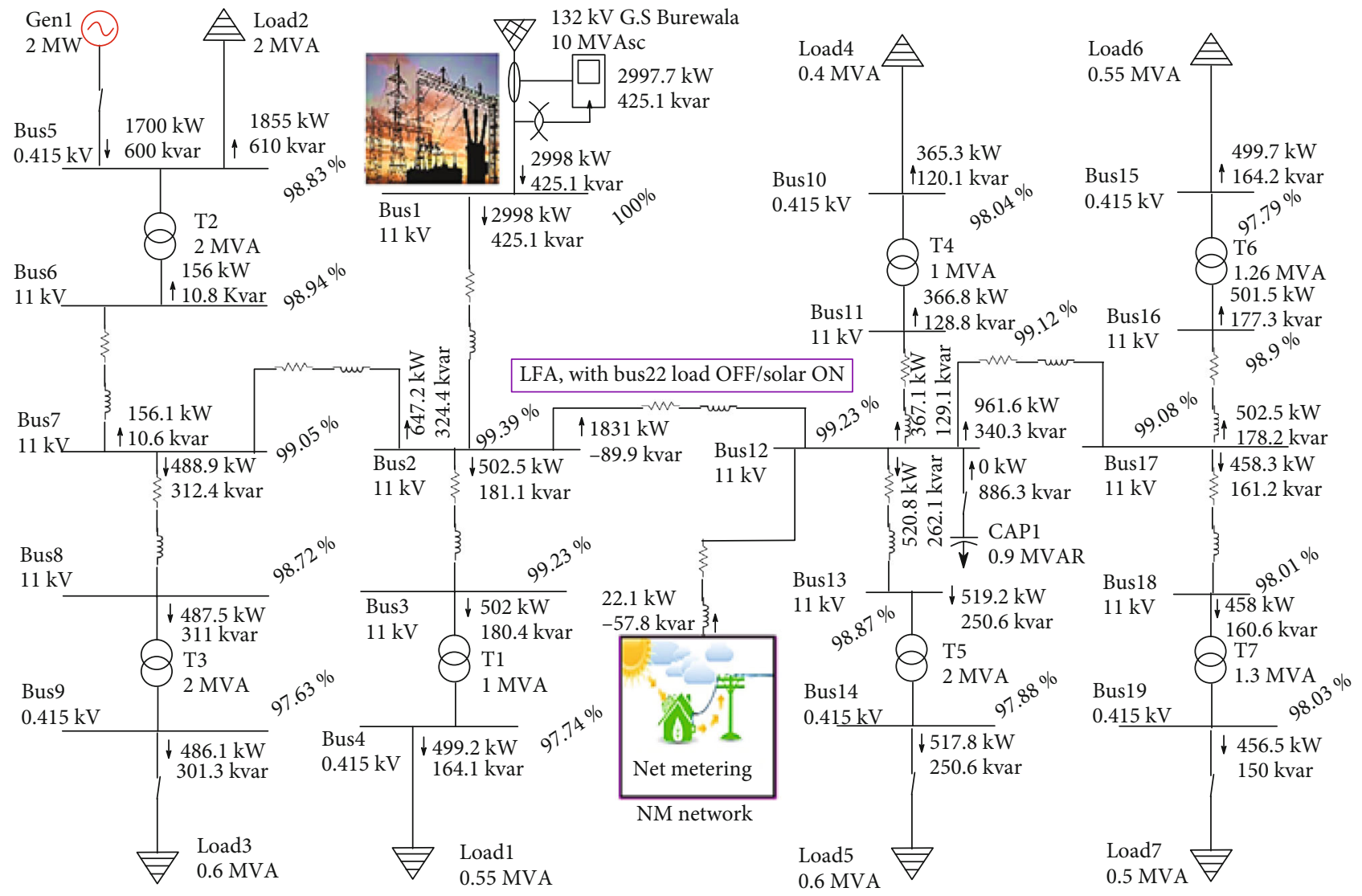

(a)

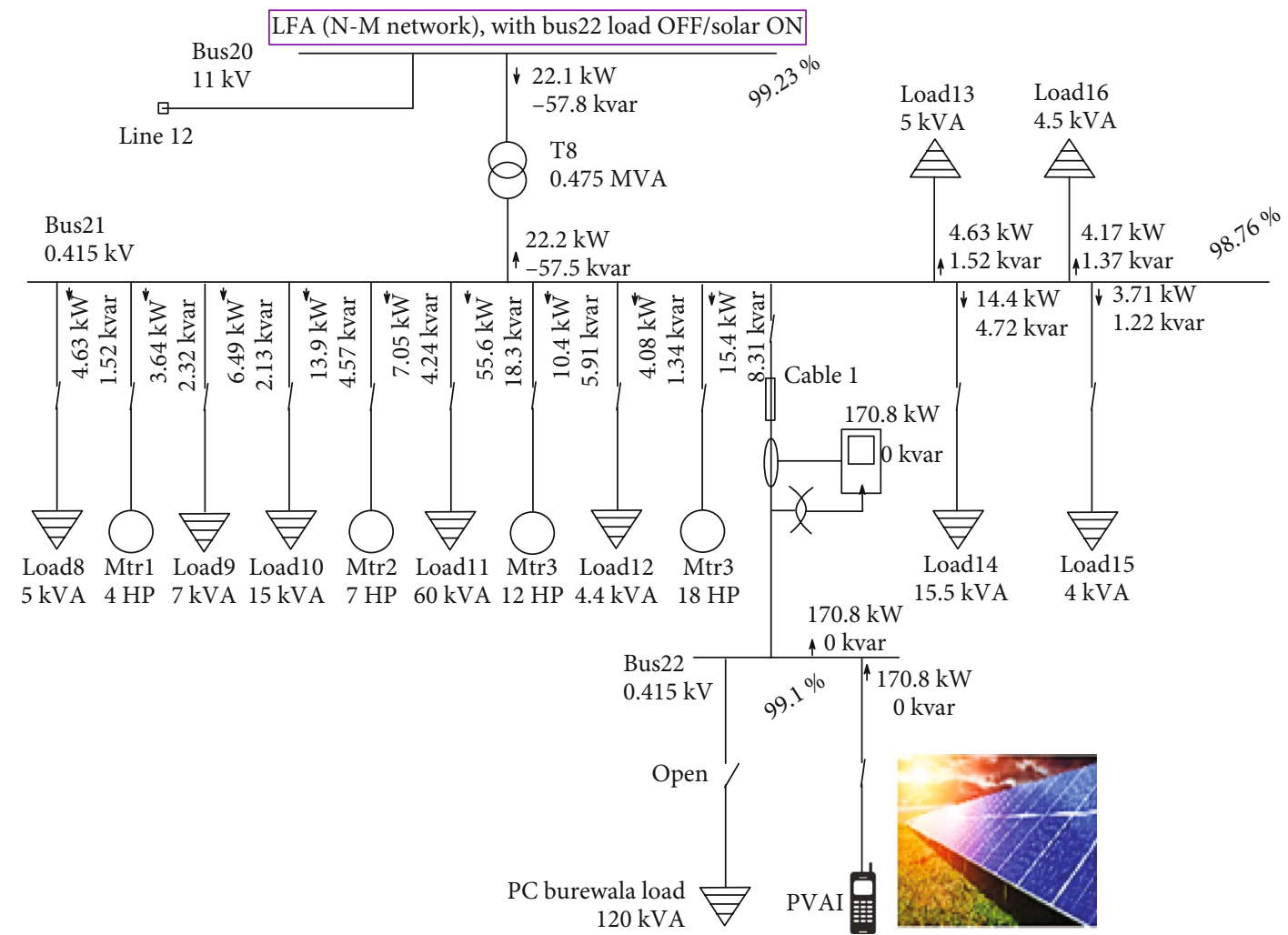

(b)

FIgURE 5: (a) Load flow analysis with Bus22 load OFF/solar ON. (b) Load flow analysis (N-M network) with Bus22 load OFF/solar ON. 
TABLE 11: Voltage profile in Case 3.

\begin{tabular}{lcc}
\hline Bus ID & Nominal voltage $(\mathrm{V})$ & Observed voltage level (\% age) \\
\hline Bus1 & 11000 & 100 \\
Bus2 & 11000 & 99.41 \\
Bus3 & 11000 & 99.23 \\
Bus4 & 415 & 97.74 \\
Bus5 & 415 & 98.83 \\
Bus6 & 11000 & 98.94 \\
Bus7 & 11000 & 99.05 \\
Bus8 & 11000 & 98.72 \\
Bus9 & 415 & 97.63 \\
Bus10 & 415 & 98.04 \\
Bus11 & 11000 & 99.12 \\
Bus12 & 11000 & 99.23 \\
Bus13 & 11000 & 98.87 \\
Bus14 & 415 & 97.92 \\
Bus15 & 415 & 97.79 \\
Bus16 & 11000 & 98.9 \\
Bus17 & 11000 & 99.13 \\
Bus18 & 11000 & 99.01 \\
Bus19 & 11000 & 98.03 \\
Bus20 & 11000 & 99.23 \\
Bus21 & 415 & 98.76 \\
Bus22 & 415 & 99.1 \\
\hline & &
\end{tabular}

TABLE 12: Load flow of N-M network for Case 2.

\begin{tabular}{lcccc}
\hline \multirow{2}{*}{ Bus ID } & \multicolumn{2}{c}{ Voltage } & \multicolumn{2}{c}{ Load flow } \\
& $\mathrm{kV}$ & \% mag. & $\mathrm{MW}$ & MVAR \\
\hline 20 & 11.000 & 99.229 & -0.022 & -0.058 \\
21 & 0.415 & 98.762 & -0.022 & -0.057 \\
22 & 0.415 & 99.102 & 0.171 & 0 \\
\hline
\end{tabular}

TABLE 13: Branch losses for Case 3.

\begin{tabular}{lccc}
\hline Branch ID & $\begin{array}{c}\text { Losses } \\
\mathrm{kW}\end{array}$ & Branch ID & $\begin{array}{c}\text { Losses } \\
\mathrm{kW}\end{array}$ \\
\hline Line1 & 16.1 & Line12 & 0.6 \\
Line2 & 0.8 & Cable1 & 0.6 \\
Line3 & 2.1 & $\mathrm{~T} 1$ & 2.8 \\
Line4 & 0.2 & $\mathrm{~T} 2$ & 0.1 \\
Line5 & 1.4 & $\mathrm{~T} 3$ & 1.4 \\
Line6 & 3.0 & $\mathrm{~T} 4$ & 1.5 \\
Line7 & 0.3 & $\mathrm{~T} 5$ & 1.4 \\
Line8 & 1.6 & $\mathrm{~T} 6$ & 1.7 \\
Line9 & 0.9 & $\mathrm{~T} 7$ & 1.4 \\
Line10 & 1.0 & $\mathrm{~T} 8$ & 0.2 \\
Line11 & 0.4 & & \\
Total losses $(\mathrm{kW})$ & & & 39.5 \\
\hline
\end{tabular}

TABle 14: Voltage level comparison for all cases.

\begin{tabular}{|c|c|c|c|}
\hline Bus ID & $\begin{array}{l}\text { Case 1: when } \\
\text { Bus22 load } \\
\text { ON/solar OFF }\end{array}$ & $\begin{array}{l}\text { Case 2: when } \\
\text { Bus22 load } \\
\text { ON/solar ON }\end{array}$ & $\begin{array}{l}\text { Case 3: when } \\
\text { Bus22 load } \\
\text { OFF/solar ON }\end{array}$ \\
\hline Bus1 & $100 \%$ & $100 \%$ & $100 \%$ \\
\hline Bus2 & $99.36 \%$ & $99.39 \%$ & $99.41 \%$ \\
\hline Bus3 & $99.18 \%$ & $99.21 \%$ & $99.23 \%$ \\
\hline Bus4 & $97.69 \%$ & $97.72 \%$ & $97.74 \%$ \\
\hline Bus5 & $98.78 \%$ & $98.81 \%$ & $98.83 \%$ \\
\hline Bus6 & $98.89 \%$ & $98.92 \%$ & $98.94 \%$ \\
\hline Bus7 & $99 \%$ & $99.03 \%$ & $99.05 \%$ \\
\hline Bus8 & $98.66 \%$ & $98.69 \%$ & $98.72 \%$ \\
\hline Bus9 & $97.58 \%$ & $97.61 \%$ & $97.63 \%$ \\
\hline Bus10 & $97.95 \%$ & $98 \%$ & $98.04 \%$ \\
\hline Bus11 & $99.03 \%$ & $99.08 \%$ & $99.12 \%$ \\
\hline Bus12 & $99.14 \%$ & $99.19 \%$ & $99.23 \%$ \\
\hline Bus13 & $98.78 \%$ & $98.83 \%$ & $98.87 \%$ \\
\hline Bus14 & $97.83 \%$ & $97.88 \%$ & $97.92 \%$ \\
\hline Bus15 & $97.7 \%$ & $97.75 \%$ & $97.79 \%$ \\
\hline Bus16 & $98.8 \%$ & $98.86 \%$ & $98.9 \%$ \\
\hline Bus17 & $99.03 \%$ & $99.08 \%$ & $99.13 \%$ \\
\hline Bus18 & $98.91 \%$ & $98.96 \%$ & $99.01 \%$ \\
\hline Bus19 & $97.94 \%$ & $97.99 \%$ & $98.03 \%$ \\
\hline Bus20 & $99.06 \%$ & $99.15 \%$ & $99.23 \%$ \\
\hline Bus21 & $97.78 \%$ & $98.18 \%$ & $98.76 \%$ \\
\hline Bus22 & $97.55 \%$ & $98.3 \%$ & $99.1 \%$ \\
\hline
\end{tabular}

TABLE 15: Branch losses comparison for all cases.

\begin{tabular}{lc}
\hline Case no. & $\begin{array}{c}\text { Total branch losses } \\
\text { of feeder }\end{array}$ \\
\hline Case 1: when Bus22 load ON/solar OFF & $45.6 \mathrm{~kW}$ \\
Case 2: when Bus22 load ON/solar ON & $40.5 \mathrm{~kW}$ \\
Case 3: when Bus22 load OFF/solar ON & $39.5 \mathrm{~kW}$ \\
\hline
\end{tabular}

main load Bus 21 of N-M network is $98.18 \%$, while in Case 1 , the voltage profile on Bus 21 was $97.78 \%$ which clearly depicts that by only single solar net-metering user, a $0.4 \%$ improvement can be seen in voltage profile on Bus21. Voltage profile on associated load Bus22 of N-M network is $98.3 \%$, while in Case 1 , the voltage profile on Bus 22 was $97.55 \%$ which shows $0.75 \%$ improvement in voltage profile on user's load Bus 22 . A complete feeder load drawn from the utility grid is $3105 \mathrm{~kW}$ but in actual, the total load of the feeder is $3274 \mathrm{~kW}$ as shown in Figure 4(a). The difference is covered by the solar netmetering mechanism which reduces the burden on the grid station as well as the dependency of the user's on the utility grid.

Branch losses in Case 2: Table 9 shows the total branch losses of the system in Case 2 when PC Burewala load $\mathrm{ON} /$ solar $\mathrm{ON}$ are $40.5 \mathrm{~kW}$, while in previous case when solar was OFF were $45.6 \mathrm{~kW}$ and which shows that power generation through solar net-metering reduces losses in a distribution network. The Table 10 shows the clear impact of 


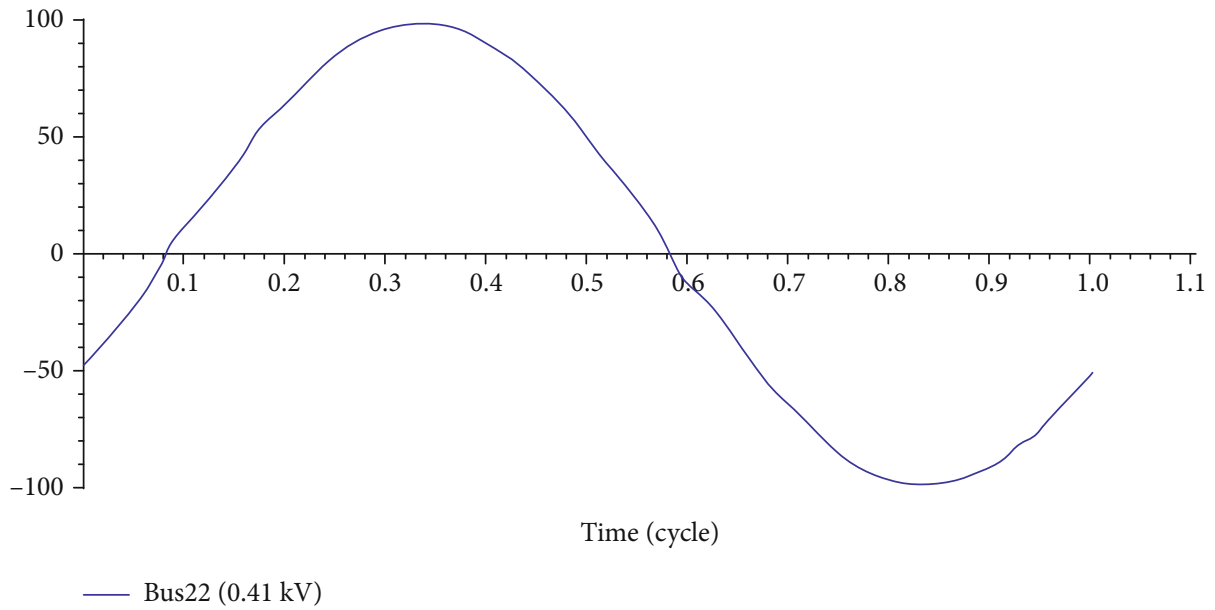

Figure 6: Output wave representation at PV Bus22.

the solar net-metering mechanism on the reduction of losses in a distribution network by the comparison of Case 1 and Case 2.

4.3. Case 3: Load Flow Analysis with Bus22 Load OFF/ Power. In Case 3, a consumer is not using any power, i.e., not at home. So, there will be no power consumption at consumer premises, but solar is generating power, i.e., solar $\mathrm{ON}$, when all generated power by solar energy will be exported to the grid as shown in Figures 5(a) and 5(b). This case is performed to check how the system will behave when all the generated energy from the solar system is fed to the utility grid.

From Figure 5(b), it can be seen that solar system is generating $170.8 \mathrm{~kW}$ and there is no any consumption of power at consumer premises because the PC Burewala load on Bus 22 is OFF, i.e., weekend or holidays. In this case, the complete generated power from the solar system is fed to the distribution grid. The multi-meter on consumer side with installed solar net-metering mechanism shows a positive active power of $170.8 \mathrm{~kW}$ which means that the consumer is exporting all the generated power to the utility grid.

The voltage profile on Bus 21 is $98.76 \%$, while in Case 2, it was $98.18 \%$ that means there is a further $0.58 \%$ improvement in voltage profile on Bus 21 of the utility grid. By comparing the Case 3 with the Case 1 when the voltage profile was $97.78 \%$ on Bus 21 , a difference of $0.98 \%$ is observed which is improved by an only single solar net-metering user. Table 11 shows the comparison of nominal voltages and the observed voltage profile at different busses in Case 3.

The load flow report in Table 12 shows the load flow and voltage profile on relevant buses of the net-metering network for Case 3.

The above Table 12 shows the load on Bus 22 is OFF, and the solar is generating power of $170.8 \mathrm{~kW}$ on Bus 22 and is being exported to the utility grid. The voltage profile on load Bus21 of the N-M network is $98.76 \%$, while in the previous case, the voltage profile on Bus 21 was $98.18 \%$. So, in this case, there is $0.58 \%$ improvement in voltage profile. A complete load drawn from the utility grid in this case is $2998 \mathrm{~kW}$, while in Case 2, it was $3105 \mathrm{~kW}$ and, in Case 1, it was $3274 \mathrm{~kW}$.
The total branch losses of the system in Case 3 shown in Table 13, when Bus22 load OFF/solar ON are much improved form previous case that $39.5 \mathrm{~kW}$, while in Case 2, the losses were $40.5 \mathrm{~kW}$, and in Case 1, the losses were $45.6 \mathrm{~kW}$. This clearly depicts that mechanism of a netmetering scheme for feeding extra power/complete power to the utility shows that the bidirectional flow of power (from the utility grid side to consumer side and vice versa) is beneficial for both a consumer and for a power system from the losses point of view.

\section{Overall Voltage Profile and Branch Losses Comparison for all Cases}

5.1. Overall Voltage Profile Comparison at Buses for all Cases. The voltage profile comparison for all three cases is shown in Table 14. It can be seen that there is a notable improvement in voltage profile in Case 2 by Case 1 and more improvement in Case 3 by Case 2, which means as more as the solar is feeding to the utility grid by a solar net-metering mechanism, the more will be the improvement in voltage profile.

5.2. Overall Branch Losses Comparison for all Cases. The overall branch losses comparison for all Cases shows in Table 15 depicts that the more the solar power is feeding to the utility grid by a solar net-metering mechanism, the more reduction in branch losses in a distribution network is observed.

\section{Harmonic Analysis}

Whenever power is exported to the grid through a solar netmetering scheme, there is always a probability of harmonics generation in a power system that causes some harmful effects on a power system. The power produced by solar energy is DC in nature which is converted into AC with the help of invertor. An inverter is a nonlinear device with the hallmarks of harmonics generation. The harmonics generation within any system can cause some serious problems, i.e., overheating of transmission lines and increased magnetic 
TABLE 16: System harmonics bus information.

\begin{tabular}{lccc}
\hline Bus ID & $\begin{array}{c}\text { Total harmonics } \\
\text { distortion (\%) }\end{array}$ & Bus ID & $\begin{array}{c}\text { Total harmonics } \\
\text { distortion (\%) }\end{array}$ \\
\hline Bus1 & 0.14 & Bus12 & 0.15 \\
Bus2 & 0.14 & Bus13 & 0.15 \\
Bus3 & 0.15 & Bus14 & 0.14 \\
Bus4 & 0.13 & Bus15 & 0.14 \\
Bus5 & 0.08 & Bus16 & 0.15 \\
Bus6 & 0.13 & Bus17 & 0.15 \\
Bus7 & 0.14 & Bus18 & 0.15 \\
Bus8 & 0.14 & Bus19 & 0.14 \\
Bus9 & 0.14 & Bus20 & 0.14 \\
Bus10 & 0.14 & Bus21 & 1.12 \\
Bus11 & 0.15 & Bus22 & 1.15 \\
\hline
\end{tabular}

losses in transformers. According to NEPRA regulations for the interconnection to the grid through solar net-metering, the allowable total harmonic distortion (THD) is up to $2.5 \%[4]$.

Authorized vendor for installation of the solar system in MEPCO circle used ABB inverter. In harmonics analysis, ABB solar harmonic model is used for analysis. The output sine wave Bus22 after harmonic distortion is shown below in Figure 6. It can be seen that there are little distortions in sine wave due to the harmonics on Bus22 resulting voltage drop in the power system. As prescribed by NEPRA netmetering regulations, these distortions are in acceptable limits of up to $2.5 \%$ [4].

6.1. Harmonic Results Report. It can be seen from harmonics analysis results as shown in Table 16 that the maximum harmonics in the system existing on solar net-metering user's Bus 22 is $1.15 \%$ only which are under acceptable limit (2.5\%) as prescribed by NEPRA [4].

\section{Conclusion}

Many countries around the world are adopting renewable energy sources as the primary source of power generation. Due to the increase in energy demand, many countries around the world are facing energy crises. Out of which, Pakistan is also facing energy crises. Pakistan is blessed with the large potential of solar energy. The only need is to promote solar energy at individual level. The best available and eye-catching way to promote solar energy is through netmetering mechanism. In this paper, the effect of a netmetering scheme was observed under different conditions, i.e., when solar is off and when solar is on. The two major analyses, i.e., load flow analysis and harmonics analysis, are performed. The load flow study of complete feeder with solar ON clearly shows multiple benefits, i.e., exporting extra energy to the utility grid, voltage profile improvement, less depending on a utility grid, reduction of system losses, and getting credit for feeding surplus energy. The mechanism of a solar net-metering scheme for feeding extra power to the distribution grid clearly depicts that the bidirectional flow of power (from the utility grid side to consumer side and vice versa) is beneficial for both a consumer and for a power system due to its multiple number of advantages. From harmonics analysis, it is concluded that the integration of solar energy through solar net-metering mechanism with distribution system is not harmful, because THD was in permissible limit, i.e., 2.5\%. Hence, a solar net-metering technique can completely eliminate the energy crises of Pakistan.

\author{
Abbreviations \\ AEDB: Alternative energy development board \\ CERA: Cyprus energy regulatory authority \\ COD: Commercial operation date \\ DISCOS: Distribution companies \\ ERC: Energy regulatory commission \\ IRR: Implementing rules and regulation \\ MEPCO: Multan electric power company \\ NEPRA: National Electric Power Regulatory Authority \\ N-M: Net-metering \\ NREB: National Renewable Energy Board \\ PC: $\quad$ Punjab College \\ QASP: Quaid-e-Azam Solar Park \\ REA: Renewable energy act \\ RES: $\quad$ Renewable energy sources \\ THD: Total harmonic distortion.
}

\section{Data Availability}

The data used to support the findings of this study are included within the article. The data is cited at relevant places within the text as references.

\section{Conflicts of Interest}

The authors declare that they have no conflicts of interest.

\section{References}

[1] N. Hameed, "Solutions for Energy Crisis in Pakistan," Solutions to Energy Crisis in Pakistan, vol. 2, 2015one-day Natl. Work..

[2] M. Irfan, Z.-Y. Zhao, M. Ahmad, and M. Mukeshimana, "Solar Energy Development in Pakistan: Barriers and Policy Recommendations," Sustainability, vol. 11, no. 4, p. 1206, 2019.

[3] F. Umer, M. S. Aslam, M. S. Rabbani, M. J. Hanif, N. Naeem, and M. T. Abbas, "Design and optimization of solar carport canopies for maximum power generation and efficiency at Bahawalpur," International Journal of Photoenergy, vol. 2019, 8 pages, 2019.

[4] NEPRA, State of Industry, 2018, National Electric Power Regulatory Authority, Government of Pakistan, 2018.

[5] H. S. Bedi, N. Singh, and M. Singh, "A technical review on solar-net metering," in 2016 7th India International Conference on Power Electronics (IICPE), Patiala, India, Nov. 2016.

[6] F. Muhammad, M. Waleed Raza, S. Khan, and F. Khan, "Different Solar Potential Co-Ordinates of Pakistan," Innovative Energy \& Research, vol. 6, no. 2, 2017. 
[7] K. A. Alboaouh and S. Mohagheghi, "Impact of rooftop photovoltaics on the distribution system," Journal of Renewable Energy, vol. 2020, 23 pages, 2020.

[8] AEDB, Alternative Energy Development Board, Ministry of Water and Power, Government of Pakistan, 2018, http://www .aedb.org/index.php/ju-elibrary/distributed-generation/netmetering-reference-guide-for-the-discos.

[9] A. Khaliq, A. Ikram, and M. Salman, "Quaid-e-Azam Solar Power park: Prospects and challenges," in 2015 Power Generation System and Renewable Energy Technologies (PGSRET), Islamabad, Pakistan, June 2015.

[10] E. Doris, S. Busche, and S. Hockett, "Net Metering Policy Development and Distributed Solar Generation in Minnesota: Overview of Trends in Nationwide Policy Development and Implications of Increasing the Eligible System Size Cap," National Renewable Energy Lab. (NREL) Tech. Reports, Golden, CO (United States), 2009.

[11] R. Pacudan, "The economics of net metering policy in the Philippines," International Energy Journal, vol. 18, no. 3, pp. 283296, 2018.

[12] A. I. Nikolaidis and C. A. Charalambous, "A critical analysis of the net metering practice in cyprus," in 2016 IEEE International Energy Conference (ENERGYCON), Leuven, Belgium, Apr 2016.

[13] B. Yosiana, The Rise of the Energy Prosumers in the ASEAN, 2018.

[14] N. Redfield and J. Redfield, "The garage of the future: maximizing the economic value of solar panels," in 2010 IEEE Green Technologies Conference, Grapevine, TX, USA, April 2010.

[15] B. Vikas, "Net metering for rooftop solar system: a review," International Journal for Research in Applied Science and Engineering Technology, vol. 6, no. 3, pp. 524-528, 2018.

[16] A. Sharma, K. Srivastava, and S. K. Kar, "Jawaharlal Nehru national solar mission in India," Green Energy Technology, vol. 201, pp. 47-67, 2015.

[17] MEPCO, Multan Electric Power Company, Feeder Wise, http://www.mepco.com.pk/net-metering-feeder-wise. 